\title{
ADOLESCENTES QUE COCHILAM: ESTUDO DE BASE POPULACIONAL EM CAMPINAS, SÃO PAULO
}

\author{
Cristina Kano Inazumi ${ }^{1}$ \\ Carla R.S. Andrechuk ${ }^{1}$ \\ Cleber S. Oliveira ${ }^{1}$ \\ Denise C.V. Freitas ${ }^{1}$ \\ Tania A.M.O. Cardoso ${ }^{2}$ \\ Edilson Zancanella ${ }^{2}$ \\ Marilisa B.A. Barros ${ }^{2}$ \\ Margareth G. Lima \\ Maria Filomena Ceolim ${ }^{1}$ \\ ${ }^{1}$ Faculdade de Enfermagem, Universidade Estadual de Campinas, Campinas, SP \\ ${ }^{2}$ Faculdade de Ciências Médicas, Universidade Estadual de Campinas, Campinas, SP
}

INTRODUÇÃO: Adolescentes têm necessidade aumentada de horas de sono devido a mudanças fisiológicas e atraso de fase dos ritmos biológicos, como o ciclo vigília/sono. Podem ocorrer cochilos não intencionais possivelmente associados à privação de sono e sonolência diurna. OBJETIVOS: Analisar a prevalência de cochilos não intencionais em função da disposição ao acordar e número de horas de sono necessárias para se sentir bem disposto durante o dia; comparar a alocação temporal do sono durante a semana e finais de semana. MÉTODO: Trata-se de recorte do estudo Inquérito de Saúde no Município de Campinas (SP), Brasil (ISACamp) realizado em 2013/2014. Participaram 1.032 adolescentes. Os dados foram coletados com questionário estruturado, testado e aplicado em domicílio por entrevistadores treinados. A variável dependente foi o relato de cochilo não intencional e as independentes foram idade, sexo, estimativa de horas de sono necessárias e disposição ao acordar. Utilizou-se estatística descritiva, teste Quiquadrado e valor de $p<0,05$ como nível crítico. Os dados foram analisados no programa STATA, versão 11.0. Aprovado no CEP (Parecer 2.584.492). RESULTADOS: dados válidos foram obtidos de 935 adolescentes (10 a 19 anos, média 14,2 anos), 50,8\% do sexo masculino. A prevalência de cochilo não intencional foi de 3,1\%; $96,9 \%$ relataram não cochilar ou cochilar intencionalmente; $78,6 \%$ sentiam-se sempre ou quase sempre dispostos ao acordar pela manhã. 0 cochilo não intencional foi associado à ausência de disposição ao acordar $(p<0,001)$ e maior número médio de horas estimadas necessárias para sentir-se disposto durante $o$ dia $(p=0,030)$. A maioria $(44,2 \%)$ estimou a necessidade de 9 ou mais horas de sono para sentir-se disposto durante o dia. Entre os que não cochilam ou cochilam intencionalmente essa média foi de 8,8 horas e para os que cochilam não 
intencionalmente, de 12,6 horas. Os adolescentes apresentaram média de horário de dormir às 23 h05 durante a semana e às 00h14 no final de semana e o horário de acordar às $07 \mathrm{~h} 30$ e às $09 \mathrm{~h} 44$ durante a semana e no final de semana, respectivamente. CONCLUSÕES: Adolescentes que cochilam não intencionalmente parecem necessitar de maior número de horas de sono para sentirem-se dispostos durante o dia, o que indicaria que tais necessidades não têm sido atendidas e que há privação de sono entre eles.

Palavras-chave: Sono. Adolescentes. Privação do sono. 